\title{
Major Selection among Saudi Male University Students: a Multinomial Logit Model
}

\author{
Guoping Jiang*
}

\author{
Department of General Studies, King Fahd University of Petroleum and Minerals, Dhahran, 31261, Saudi \\ Arabia
}

\begin{abstract}
Major selection is an important decision faced by all university freshmen. The topic has been studied thoroughly in individualistic cultures, particularly the US and Europe. The topic has not been as intensely investigated in the Middle East, an area influenced heavily by Islamic collectivist culture. Because of digital media and globalization, the Middle East is shifting toward individualism. Given this, we used a sample of male students at a science and engineering university to explore mechanisms that drive major selection in Saudi Arabia. A multinomial logistic analysis shows that family and high school teachers are important factors in their decision making process. Ease of study is also a factor considered when choosing a major.
\end{abstract}

Keywords: Collectivist culture, social influences, major selection, multinomial logit model, male university students, Saudi Arabia.

\section{INTRODUCTION}

After admission college students face the decision of major selection, which affects the remainder of their college experience, and has long-term, post-graduation consequences. At the time of major selection, college students are susceptible to pressure, ideas, and values that alter the way they think, act, and perceive experiences and opportunities. Therefore, in the major selection process, many factors may influence their decision making, including family influence, peer influence, and social influence. These influences are deeply explored in American and European societies(Kumar and Kumar 2013; Chen, Jones, and Mclntyre 2005; Lobb, Shah, and Kolassa 2004; Beggs, Bantham, and Taylor 2008; Calkins and Welki 2006), but rarely in the Middle East. The Middle East differs significantly from western societies in terms of culture and value systems. The findings from US and Europe may not be applicable to Islamic societies which are commonly defined as collectivistic in nature (Jiang, Garris, and Bendania 2010). Saudi Arabia, the cradle of Islam, has been experiencing a decades-long economic boom after the discovery of oil in the 1930s. Education in Saudi Arabia has developed dramatically since then. Twenty-one government universities and 24 private universities are located across the provinces of the Kingdom (Saudi Ministry of Higher Education 2014). These universities provide all kinds of programs which receive different popularities. So far only a very small body of studies (Almandil and Alkhathlan 1990;

*Address correspondence to this author at the Department of General Studies, King Fahd University of Petroleum and Minerals, Dhahran, 31261, Saudi Arabia; Tel: 00966-13-8607411; Fax: 00966-13-8607471;

E-mail: jiang@kfupm.edu.sa
Aldosary and Assaf 1996) have explored factors which play an important role in Saudi students' selection of their college major in the 1990s. Saudi society has experienced considerable change since that time. Globalization, industrialization, and digital mass media, such as internet, are reshaping Saudi society. The findings from the 1990s may not be applicable to Saudi college students in $21^{\text {st }}$ century. Therefore, it is worth revisiting the topic after 20 years of change. Another reason why the study is important to the field because the author used multinomial logistic regression instead of linear regression to revisit the topic giving readers a detailed comparison among majors. This study helps understand what determines Saudi male students' selection of their college major in the globalized $21^{\text {st }}$ century. Female college students are not covered in the study because of sex segregation in Saudi Arabia and the impossibility of data collection.

\section{LITERATURE REVIEW}

Scholars from various fields have shown interest in the selection of college majors. Their empirical approaches and emphases on specific academic fields vary (Beggs, Bantham, and Taylor 2008; Malgwi, Howe, and Burnaby 2005; Walstrom et al. 2008). Across these approaches, many factors have been identified which impact students' major selection (Noël, Michaels, and Levas 2003; Cho, Jones, and Olsen 2008; Ko et al. 2007; Pritchard, Potter, and Saccucci 2004; Leppel, Williams, and Waldauer 2001; Kim, Markham, and Cangelosi 2002). These factors center on job, family, peer, media, and area of study. However, impacts of such factors on student's decision are moderated by dominant culture in the society. 
Societies can be divided into individualist and collectivist in terms of cultural dimension (Desai 2006). Individualists like to draw sharp boundaries between people seeing each person as a complete unit. It holds that individual is sovereign, an end in himself. In individualist societies such as Europe and North America, affluence, autonomy, independence, individual uniqueness, and self-determination are emphasized and valued (Skillman 1999). Social status is also awarded to personal accomplishments which make an individual standing out and distinct. Thus, people always feel there is a need to assert and express the self. Personal experiences such as accomplishments, challenges, career, and relationships with other people are of great significance to one's identity (Markus and Kitayama 1991). Such a culture tend to result in a strong sense of competition for it emphasizes personal achievement regardless of the expense of group goals.

Collectivist cultures, conversely, emphasizes embeddedness of individuals in a larger group and expect people to identify with and work well in groups which protect them in exchange for loyalty and compliance. Their identity is mainly based on their roles and experiences within the group context. Muslim and Asian societies are noted for collectivist culture. They value family cohesion, cooperation, solidarity, and conformity and focus on what people have in common (Skillman 1999). People in collectivistic societies tend to make more references to others, emphasize group goals, and meet the expectations of the group (Desai 2006). In extreme situations, one may need to sacrifice his values and goals for the group's "greater good" although inevitably there is usually one person who actually makes the decision that is presented to the "community" as the greater good. Decisions by authority figures in collectivist cultures are likely to be obeyed with less questioning than in typical individualistic cultures.

Islam is a typical collectivist culture that stresses the importance of working for the collective good, taking care of others and maintaining unity in the face of opposition or threat. It encourages betterment of society and harmony in the community and discourages social freedom which gives individuals carte blanche to achieve their objectives at the expense of the larger community. Within the ummah (Muslim community), family is the fundamental building block and social hub with ties of kinship valued. Social hierarchies based on gender, birth order, and/or age are followed and respected. For instance, family elders often have roles of authority with responsibility, and therefore have a final say on various things of younger generation such as the school they attend, whom they marry, or where they work. Such a traditional culture works as a mechanism of moderation between their own interests and decision.

Family has always been considered to be a significant factor on social development (Bandura 1977). University freshmen do not yet seem to be independent from their parents psychologically. According to identity theory (Marcia 1966; Petitpas 1978), college students' commitment is given or handed down by their parents because they like to identify with their parents at the identity foreclosure stage. Therefore, the support and suggestions of one's father or mother are crucial in their decision of major selection(Chung, Loeb, and Gonzo 1996; Newell, Titus, and West 1996). Fitzpatrick and Silverman (1989) investigate whether certain background and motivational differences noted in the research of the 70 s would remain in the 80 s with a sample of three groups of high achieving female college students who were majoring in engineering, science, humanities, and social sciences. Differences were found only in sources of parental support and work characteristics (job availability and salary). Pearson and Dellman-Jenkins (1997) also discover significant group differences in major selection because of parental encouragement and other family structure variables, such as working status of mother and/or stepmother, residential status of father and/or stepfather. However, in an Islamic environment which stresses family and community, parental influence is not found to be a consistently strong predictor of students' major selection. In both the studies of Almandil and Alkhathlan (1990) and Aldosary and Assaf (1996), parental influence is not verified to be an important factor in the process of major selection. However, Al-Rfou (2013) finds that parents have a significant influence on the selection of college major, in addition to the influence of siblings and friends. A related study of Malaysian secondary school students reveals that parents, mothers in particular, are more influential in their career choice than peer influence (Hashim and Embong 2015).

There is a large body of literature that documents the importance of peer influence on adolescent choices. Peer influence, as a socialization process, motivates exchange of information, imitation or role modeling, and is reinforced by norms (Hallinan and Williams 1990). It has been demonstrated that the peer group has a significant effect on students' beliefs and 
behaviors in school, as well as on academic achievement (Walker 2006; Coleman et al. 1966). Besides academic achievement, peers also influence several other educational outcomes, such as enrollment in college(Fletcher 2013), choice of college major (Lyle 2007), and choosing to join a fraternity (Sacerdote 2000).Hashim and Embong (2015) discover that Malaysian Muslim students choose commerce majors because of friends, and female students are more influenced by their peers than male students. Among Saudi students, peer influence is not found to be a significant predictor of their major selection (Aldosary and Assaf 1996).

Occupations, colleges, majors, and programs are discussed, compared, and analyzed in newspapers, radio, magazine, and the Internet. Younger generations are exposed to mass media more than older generations(Ahuja 2013; Miller 2014). It is, therefore, understandable that media have tremendous impacts on the behavior and minds of youth (McLeod 2000). Crampton, Walstrom, and Schambach (2006) find that the Internet, newspapers, and TV are rated as the top information sources which influence the choice of college major. Sometimes media have no direct information on college majors, but figures in TV drama and movies create an image of particular occupation and major which influences college students' major selection later (Cho, Jones, and Olsen 2008). In contrast to American or European societies, Al-Rfou (2013) finds that media is among the least influential factors on the selection of college majors in Jordan, even though Jordanian Muslim students are exposed to considerable media influences.

In students' eyes, their teachers are more experienced regarding college majors and have more insights about occupations. Teacher influence has been shown to be widespread among American accounting students (Violette and Chene 2012). From African American students sampled from a mid-west university, John-Charles and Walstrom (2000) discover that teacher influence on major selection is stronger than other factors. Kumar and Kumar (2013) suggest that such influence may not be enormously strong, but does have impact on students' major selection. Different from the findings from American data, high school teachers in Jordan have limited influence on students' major selection(Al-Rfou 2013). A similar result is found for students in Saudi Arabia (Almandil and Alkhathlan 1990; Aldosary and Assaf 1996).

Job characteristics, such as job availability, the social image of an occupation, and earning potential, are always concerns of students while selecting their majors. Following the logic of expectancy theory(Vroom 1964), many scholars (Brooks and Betz 1990; Kumar and Kumar 2013) predict that college students' occupational preferences and occupational choices rely on students' evaluation of the desirability of various career-related outcomes and the ability of different careers to provide those outcomes. The most commonly desired outcome, monetary rewards, significantly predicts major selection in many studies, regardless of whether considering long-term or shortterm earning (Simons, Lowe, and Stout 2003; Mauldin, Crain, and Mounce 2000; Lobb, Shah, and Kolassa 2004). Chen, Jones and Mclntyre (2005) also show that accounting and non-accounting majors did not differ significantly on the level of importance placed on longterm earnings. Besides pecuniary rewards, the social prestige of an occupation - a factor embedded in culture - is valued significantly in students' major selection (Zhan 2013; Lobb, Shah, and Kolassa 2004). Students choose majors for the potential for a well-paid and respectable job not only in Western societies, but also in the Middle East. Both Aldosary and Assaf (1996) and Al-Rfou (2013) find that future earning, career options, occupational prestige and type of work are the most important factors that affect the selection of college majors among Arab students. Job stability is another factor that influences major selection in various societies (Cho, Jones, and Olsen 2008; Crampton, Walstrom, and Schambach 2006; Simons, Lowe, and Stout 2003; Mauldin, Crain, and Mounce 2000; Sugahara, Boland, and Cilloni 2008; Aldosary and Assaf 1996). A typical example is the drastic decline in enrolled accounting students because of spurring concern about the future of the profession in US in 1990s (Albrecht and Sack 2000).

Student's immediate goal is to complete their studies, graduate and earn a degree. As a result, understanding their own academic ability plays a role in their choice of major. Students are more likely to choose a major that they think can be successfully completed. Salawu and Bagudo (2008) report a strong positive relationship between students' self-concept and their major selection/career choice in a sample of Nigerian students. Bergeron and Romano (1994) also demonstrated that students' perceptions about their abilities and their feelings of self-efficacy seem to play a role in major selection.

Prior studies show that various types of influential factors are associated with a student's selection of college major. However, the findings of these studies 
have not provided sufficient evidence to address the topic in Saudi Arabia, where Islamic culture prevails, but is changing due to globalization and industrialization. Moreover, prior studies in the Middle East used only descriptive statistics or simple linear regression to test the strength of these predictive factors. The findings reported in the literature are not consistent, suggesting that additional work is needed. Our study seeks to understand Saudi male university students' selection of college major in the $21^{\text {st }}$ century with variables identified in literature.

\section{METHODS}

The data for the study was collected via a selfconstructed questionnaire completed by students taking general education courses (required for all students) at a top-national technological male university in Saudi Arabia. Reputation of the University associated to job opportunity attracts talented youth from all regions of Saudi Arabia, which guarantees representativeness of samples to some extent. Of the 250 students sampled, 233 complete questionnaires were obtained. All respondents are Muslim with $47.1 \%$ in the college of engineering, $41.3 \%$ in the college of computer science, and $7.6 \%$ in the college of industrial management (Table 1).

Table 1: Percentage of Respondents by College

\begin{tabular}{|c|c|c|}
\hline & Frequency & Valid Percent \\
\hline \hline College of science & 2 & 0.9 \\
\hline College of engineering & 110 & 47.1 \\
\hline College of computer science & 96 & 41.3 \\
\hline $\begin{array}{c}\text { College of industrial } \\
\text { management }\end{array}$ & 18 & 7.6 \\
\hline College of environmental design & 7 & 3.1 \\
\hline Total & 233 & 100 \\
\hline
\end{tabular}

The questionnaire is based on prior studies including independent variables parental influence, peer influence, media influence, teacher influence, job characteristics, and how easy the major course of study is perceived. Independent variables are measured with Likert type scales with "1" representing "strongly disagree" and "7" representing "strong agree". Internal validity for each of these measurements was appropriate with all Cronbach's alphas larger than 0.7 (Table 2). The mean for variable family influence is 3.62 (Std. Dev. =1.675) referring an above medium level of interference from family (Table 2). The mean for variable peer influence and teacher influence is 3.04 (Std. Dev. =1.767) and 2.56 (Std. Dev. =1.737) respectively, which indicates only a slightly moderate influence (Table 2). A relatively high mean for variable media influence suggests that respondents receive a lot of information about college majors from media (mean=4.42, Std. Dev. =1.606, Table 2). Similarly, the mean for variable job characteristics indicates that students' majors have attractive characteristics for them (mean=4.89, Std Dev=1.021, Table 2); the mean for variable ease of study suggests that their major is not perceived as so difficult for them (mean $=3.90$, Std. Dev. $=1.251$, Table 2).

A multinomial logit analysis was conducted to examine the association of major selection with the impact of parents, peers, media, teachers, job characteristics, and ease of study. This analysis was to identify the extent to which these variables predict students' major selection, as well as how these relationships differ across major. Hypothesis is as follow: Saudi male university students' decision-making on major selection is a complicated process in which various factors including parents' opinion, peer influence, media impacts, high school teacher's opinion, job characteristics and ease of study are involved and have different impacts on it given the strong Islamic collectivist culture.

\section{FINDINGS}

The model shows that there is a statistically significant relationship between the major selection and

Table 2: Cronbach's Alpha and Composite Mean of Scales

\begin{tabular}{|c|c|c|c|}
\hline Scale & Cronbach's alpah & Composite mean & Std. Deviation \\
\hline \hline Parent influence & 0.718 & 3.62 & 1.675 \\
\hline Peer influence & 0.766 & 3.04 & 1.767 \\
\hline Teacher influence & 0.944 & 2.56 & 1.737 \\
\hline Media influence & 0.719 & 4.42 & 1.606 \\
\hline Job characteristics & 0.759 & 4.89 & 1.021 \\
\hline Ease of study & 0.724 & 3.90 & 1.251 \\
\hline
\end{tabular}


Table 3: Multinomial Logistic Regression Model Fitting Information

\begin{tabular}{|c|c|c|c|}
\hline \multirow{2}{*}{ Model } & Model Fitting Criteria & \multicolumn{2}{|c|}{ Likelihood Ratio Tests } \\
\cline { 2 - 5 } & $\mathbf{- 2}$ Log Likelihood & Chi-Square & df \\
\hline \hline Intercept Only & 479.188 & & \\
\hline Final & 428.585 & 50.603 & 24 \\
\hline
\end{tabular}

the combination of the predictor variables; the probability of chi-square for the model is significant at the level of 0.01 (Table 3).

The result of likelihood ratio test shows that only parent's influence, teacher influence, and ease of study have significant predictions on students' major selection $\left(X^{2}=15.45, p<0.01 ; X^{2}=9.84, p<0.05 ; X^{2}=10.41\right.$, $p<0.05$; Table 4). Peer influence, media influence, and job characteristics had no significant relationship with students' major selection.

Computer science major is quite popular among Saudi college students, therefore used as a reference group to check which independent variable differentiates computer science students and those from the college of engineering, and the college of industrial management.

In the comparison of engineering students to computer science students, teacher influence is statistically significant in differentiating students' major selection (Wald=7.979, $p<0.01$ ). Each unit increase in teacher influence, the odds of selecting engineering as a major increases by $32.9 \%((\operatorname{Exp}(B)=1.329$, Table 5$)$. Respondents who reported higher levels of teacher influence were more likely to choose engineering majors than computer science majors. Ease of study is also found to be statistically significant in distinguishing engineering students and computer science students in their major selection (Wald=8.244, $p<0.01$, Table 5). Each unit increase in the ease of study, the odds of selecting engineering as a major decreases by $32.5 \%$ $(\operatorname{Exp}(B)=0.675$, Table 5). Students who reported to be more influenced by the difficulty of the course of study were less likely to choose engineering majors than computer science majors.

In the comparison of industrial management students to computer science students, parent influence is statistically significant in differentiating students' major selection (Wald $=9.409, p<0.01$, Table 5). Students who receive more parental influence are more likely to choose the industrial management major rather than the computer science major. Each unit increase in parent's influence, the odds of selecting industrial management as a major increases by $101.4 \%(\operatorname{Exp}(B)=2.014$, Table 5).

In the comparison of environmental design students to computer science students, parent influence is statistically significant in differentiating students' major selection (Wald $=4.809, p<0.05$, Table 5). Students who receive more parental influence are more likely to choose an environmental design major rather than computer science major. Each unit increase in parent's influence, the odds of selecting environmental design as a major increases by $108.8 \%(\operatorname{Exp}(B)=2.088$, Table 5).

\section{CONCLUSION}

The selection of a college major is, to a great extent, about a career; therefore, it is a crucial decision

Table 4: Result of Multinomial Logistic Regression Likelihood Ratio Tests

\begin{tabular}{|c|c|c|c|c|}
\hline \multirow{2}{*}{ Effect } & \multirow{2}{*}{$\begin{array}{c}\text { Model Fitting Criteria } \\
-2 \text { Log Likelihood of Reduced Model }\end{array}$} & \multicolumn{3}{|c|}{ Likelihood Ratio Tests } \\
\hline & & Chi-Square & df & Sig. \\
\hline Intercept & 441.802 & 13.217 & 4 & 0.010 \\
\hline Parent influence & 444.037 & 15.451 & 4 & 0.004 \\
\hline Peer influence & 433.306 & 4.721 & 4 & 0.317 \\
\hline Media influence & 435.067 & 6.482 & 4 & 0.166 \\
\hline Teacher influence & 438.424 & 9.839 & 4 & 0.043 \\
\hline Job characteristics & 431.957 & 3.372 & 4 & 0.498 \\
\hline Easy of study & 438.999 & 10.414 & 4 & 0.034 \\
\hline
\end{tabular}


Table 5: Multinomial logit Regression Parameter Estimates

\begin{tabular}{|c|c|c|c|c|c|c|c|}
\hline \multicolumn{2}{|c|}{ Major by college ${ }^{a}$} & B & Std. Error & Wald & df & Sig. & $\operatorname{Exp}(B)$ \\
\hline \multirow{7}{*}{ College of science } & Intercept & -22.528 & 13.438 & 2.811 & 1 & 0.094 & \\
\hline & Familyinfluence & -0.005 & 0.636 & 0.000 & 1 & 0.993 & 0.995 \\
\hline & Peerinfluence & 0.207 & 0.593 & 0.122 & 1 & 0.727 & 1.230 \\
\hline & Mediainfluence & 2.553 & 1.949 & 1.716 & 1 & 0.190 & 12.849 \\
\hline & Teacherinfluence & 0.417 & 0.545 & 0.586 & 1 & 0.444 & 1.517 \\
\hline & Jobcharacteristics & 0.642 & 0.962 & 0.445 & 1 & 0.505 & 1.900 \\
\hline & Easy of study & -0.602 & 1.020 & 0.348 & 1 & 0.555 & 0.548 \\
\hline \multirow{7}{*}{$\begin{array}{l}\text { College of } \\
\text { engineering }\end{array}$} & Intercept & 1.051 & 0.805 & 1.706 & 1 & 0.192 & \\
\hline & Familyinfluence & 0.162 & 0.106 & 2.347 & 1 & 0.125 & 1.176 \\
\hline & Peerinfluence & -0.115 & 0.097 & 1.401 & 1 & 0.237 & 0.892 \\
\hline & Mediainfluence & -0.115 & 0.114 & 1.023 & 1 & 0.312 & 0.891 \\
\hline & Teacherinfluence & 0.285 & 0.101 & 7.979 & 1 & 0.005 & 1.329 \\
\hline & Jobcharacteristics & 0.040 & 0.173 & 0.053 & 1 & 0.818 & 1.041 \\
\hline & Easy of study & -0.393 & 0.137 & 8.244 & 1 & 0.004 & 0.675 \\
\hline \multirow{7}{*}{$\begin{array}{c}\text { College of } \\
\text { industrial } \\
\text { management }\end{array}$} & Intercept & 0.050 & 1.397 & 0.001 & 1 & 0.971 & \\
\hline & Familyinfluence & 0.700 & 0.228 & 9.409 & 1 & 0.002 & 2.014 \\
\hline & Peerinfluence & -0.265 & 0.191 & 1.937 & 1 & 0.164 & 0.767 \\
\hline & Mediainfluence & -0.040 & 0.218 & 0.034 & 1 & 0.853 & 0.960 \\
\hline & Teacherinfluence & 0.196 & 0.177 & 1.227 & 1 & 0.268 & 1.217 \\
\hline & Jobcharacteristics & -0.462 & 0.314 & 2.162 & 1 & 0.141 & 0.630 \\
\hline & Easy of study & -0.467 & 0.255 & 3.341 & 1 & 0.068 & 0.627 \\
\hline \multirow{7}{*}{$\begin{array}{l}\text { College of } \\
\text { environmental } \\
\text { design }\end{array}$} & Intercept & -1.302 & 2.295 & 0.322 & 1 & 0.571 & \\
\hline & Familyinfluence & 0.736 & 0.336 & 4.809 & 1 & 0.028 & 2.088 \\
\hline & Peerinfluence & -0.471 & 0.327 & 2.080 & 1 & 0.149 & 0.624 \\
\hline & Mediainfluence & -0.44 & 0.288 & 2.339 & 1 & 0.126 & 0.644 \\
\hline & Teacherinfluence & -0.137 & 0.328 & 0.175 & 1 & 0.676 & 0.872 \\
\hline & Jobcharacteristics & -0.206 & 0.529 & 0.151 & 1 & 0.698 & 0.814 \\
\hline & Easy of study & 0.022 & 0.361 & 0.004 & 1 & 0.952 & 1.022 \\
\hline
\end{tabular}

a. The reference category is: College of computer science.

for all university students. In this study Saudi male university students were chosen as a sample to explore which factors influence the major selection in an Islamic environment. The multinomial logit analysis shows that the students' major selection is significantly influenced by social factors. Contrary to our expectations, in the globalized $21^{\text {st }}$ century, traditional culture and collectivism still prevail in Saudi Arabia and play an important role in a college student's life. Parental influence is a key factor in Saudi university students' major selection; teacher's suggestions are also a significant consideration in their selection of a college major. In addition, the students seem to take a conservative approach in their major selection, as indicated by the influence of perceived possibility of graduation and their academic performance in school. An attractive but tough major may not be their final choice. On the contrary, peer influence, media influence and job characteristics did not meaningfully impact their major selection decision. Saudi Arabia is in an era of high speed development, which calls for all kinds of professionals. An educational policy implication of our study is that for those unpopular majors, Saudi government needs to promote via traditional cultural elements such as older generation and teacher in order to train sufficient professionals for economic boom. 
One limitation of our study is that we were only able to sample male university students due to sex segregation in Saudi Arabia and the difficulty of collecting data from female college students, or even getting in touch with female teachers from girl's college. Therefore, our conclusion may not be applicable to female Saudi university students. More studies are needed to explore gender differences in major selection among Saudi students. Another limitation is that the sample was recruited from a technological university, which lacks medicine, law, humanities and social science majors. Further studies can help compare these majors to science and engineering in terms of students' selection of a college major. Overall, this research serves as an update to existing Saudi data on major selection, and contributes to a better understanding of the unique situation of major selection that exists in Saudi Arabian tertiary education.

\section{REFERENCES}

Ahuja, Masuma 2013. "Teens are Spending More Time Consuming Media, on Mobile Devices." Retrieved August 10, 2015 (http://www.washingtonpost.com/postlive/teens-are-spendingmore-time-consuming-media-on-mobile-devices/2013/03/ 12/309bb242-8689-11e2-98a3-b3db6b9ac586_story.html).

Al-Rfou, Ahmad Nahar. 2013. "Factors that Influence the Choice of Business Major Evidence from Jordan." Journal of Business and Management 8 (2):104-8.

Albrecht, W Steve, and Robert J Sack. 2000. "Accounting Education: Charting the Course through a Perilous Future." Sarasota, FL: American Accounting Association

Aldosary, Adel S, and Sadi A Assaf. 1996. "Analysis of Factors Influencing the Selection of College Majors by Newly Admitted Students." Higher Education Policy 9 (3):215-20. http://dx.doi.org/10.1016/S0952-8733(96)00013-X

Almandil, M.Y., and A.A. Alkhathlan. 1990. "A Study of the Majors Selection Process at KFUPM." European Journal of Engineering Education 15 (1):75-9. http://dx.doi.org/10.1080/03043799008939460

Bandura, Albert. 1977. Social Learning Theory. Upper Saddle River, NJ: Prentice Hall.

Beggs, Jeri Mullins, John H Bantham, and Steven Taylor. 2008. "Distinguishing the Factors Influencing College Students' Choice of Major." College Student Journal 42 (2):381-94.

Bergeron, Lynn M, and John L Romano. 1994. "The Relationships among Career Decision-Making Self-efficacy, Educational Decision, Vocational Decision, and Gender." Journal of College Student Development 35:19-24.

Brooks, Linda, and Nancy E Betz. 1990. "Utility of Expectancy Theory in Predicting Occupational Choices in College Students." Journal of Counseling Psychology 37 (1):57-64. http://dx.doi.org/10.1037/0022-0167.37.1.57

Calkins, Lindsay Noble, and Andrew Welki. 2006. "Factors that Influence Choice of Major: Why Some Students Never Consider Economics." International Journal of Social Economics 33 (8):547-64. http://dx.doi.org/10.1108/03068290610678707

Chen, Clement, Keith T Jones, and D David Mclntyre. 2005. "A Reexamination of the Factors Important to Selection of Accounting As a Major." Accounting and the Public Interest 5 (1):14-31. http://dx.doi.org/10.2308/api.2005.5.1.14
Cho, Juyun, Susan Jones, and David Olsen. 2008. "An Exploratory Study on Factors Influencing Major Selection." Issues in Information Systems 9:168-75.

Chung, Y Barry, Jane W Loeb, and Susan T Gonzo. 1996. "Factors Predicting the Educational and Career Aspirations of Black College Freshmen." Journal of Career Development 23 (2):127-35. http://dx.doi.org/10.1177/089484539602300203

Coleman, James S, Ernest Q Campbell, Carol J Hobson, James McPartland, Alexander M Mood, Frederic D Weinfeld, and Robert York. 1966. "Equality of Educational Opportunity." Washginton, DC: U.S. Government Printing Office.

Crampton, William J, Kent A Walstrom, and Thomas P Schambach. 2006. "Factors Influencing Major Selection by College of Business Students." Issues in Information Systems 7(1):22630.

Desai, Janhavi S. 2006. "Intergenerational Conflict within Asian American Families: the Role of Acculturation, Ethnic Identity, Individualism, and Collectivism". PhD dissertation, Department of Sociology, Loyola University Chicago.

Fitzpatrick, Jody L, and Traci Silverman. 1989. "Women's Selection of Careers in Engineering: Do Traditional-nontraditional Differences still Exist?" Journal of Vocational Behavior 34 (3):266-78. http://dx.doi.org/10.1016/0001-8791(89)90019-5

Fletcher, Jason. 2013. "Social Interactions and College Enrollment: Evidence from the National Education Longitudinal Study." Contemporary Economic Policy 31 (4):762-78. http://dx.doi.org/10.1111/j.1465-7287.2012.00335.x

Hallinan, Maureen T, and Richard A Williams. 1990. "Students' Characteristics and the Peer-influence Process." Sociology of Education 63 (2):122-32. http://dx.doi.org/10.2307/2112858

Hashim, Hezlina Mohd, and Abdul Mutalib Embong. 2015. "Parental and Peer Influences upon Accounting as a Subject and Accountancy as a Career." Journal of Economics, Business and Management $3(2): 252-6$.

http://dx.doi.org/10.7763/JOEBM.2015.V3.189

Jiang, Guoping, Christopher Paul Garris, and Ahmed Bendania. 2010. "Community Involvement in Crime Prevention and Judicial Process: the Experience of Saudi Arabia." British Journal of Community Justice 8 (3):49-62.

John-Charles, G, and KA Walstrom. 2000. "Influencing African American's Decisions to Select an Information Technology Major." Journal of Computer Information Systems 41 (1):56-60.

Kim, David, F Scott Markham, and Joseph D Cangelosi. 2002. "Why Students Pursue the Business Degree: a Comparison of Business Majors across Universities." Journal of Education for Business 78 (1):28-32. http://dx.doi.org/10.1080/08832320209599694

Ko, Hin Hin, Tim K Lee, Yvette Leung, Bruce Fleming, Elena Vikis, and Eric M Yoshida. 2007. "Factors Influencing Career Choices Made by Medical Students, Residents, and Practising Physicians." British Columbia Medical Journal 49 (9):482-9.

Kumar, Anil, and Poonam Kumar. 2013. "An Examination of Factors Influencing Students Selection of Business Majors Using TRA Framework." Decision Sciences Journal of Innovative Education 11 (1):77-105. http://dx.doi.org/10.1111/j.1540-4609.2012.00370.x

Leppel, Karen, Mary L Williams, and Charles Waldauer. 2001. "The Impact of Parental Occupation and Socioeconomic Status on Choice of College Major." Journal of Family and Economic Issues 22 (4):373-94. http://dx.doi.org/10.1023/A:1012716828901

Lobb, William B, Mansi Shah, and EM Kolassa. 2004. "Factors Influencing the Selection of a Major: a Comparison of Pharmacy and Nonpharmacy Undergraduate Students." Journal of Pharmacy Teaching 11 (2):45-64. http://dx.doi.org/10.1300/J060v11n02 04 
Lyle, David S. 2007. "Estimating and Interpreting Peer and Role Model Effects from Randomly Assigned Social Groups at West Point." The Review of Economics and Statistics 89 (2):289-99.

http://dx.doi.org/10.1162/rest.89.2.289

Malgwi, Charles A, Martha A Howe, and Priscilla A Burnaby. 2005. "Influences on Students' Choice of College Major." Journal of Education for Business 80 (5):275-82. http://dx.doi.org/10.3200/JOEB.80.5.275-282

Marcia, James E. 1966. "Development and Validation of Ego-identity Status." Journal of Personality and Social Psychology 3 (5):551-8. http://dx.doi.org/10.1037/h0023281

Markus, Hazel R, and Shinobu Kitayama. 1991. "Culture and the Self: Implications for Cognition, Emotion, and Motivation." Psychological Review 98 (2):224. http://dx.doi.org/10.1037/0033-295X.98.2.224

Mauldin, Shawn, John L Crain, and Patricia H Mounce. 2000. "The Accounting Principles Instructor's Influence on Students' Decision to Major in Accounting." Journal of Education for Business 75 (3):142-8. http://dx.doi.org/10.1080/08832320009599005

McLeod, Jack M. 2000. "Media and Civic Socialization of Youth." Journal of Adolescent Health 27 (2):45-51. http://dx.doi.org/10.1016/S1054-139X(00)00131-2

Miller, Joe. 2014. "Britons Spend more Time on Tech than Asleep, Study Suggests." Retrieved August 11, 2015 (http://www.bbc.com/news/technology-28677674).

Newell, Stephen J, Philip A Titus, and James S West. 1996. "Investigating the Undergraduate Student Decision-making Process of Selecting a Business Specialization: a Comparison of Marketing and Nonmarketing Business Students." Journal of Marketing Education 18 (3):57-67. http://dx.doi.org/10.1177/027347539601800307

Noël, Noel Mark, Chad Michaels, and Michael G Levas. 2003. "The Relationship of Personality Traits and Self-monitoring Behavior to Choice of Business Major." Journal of Education for Business 78 (3):153-7. http://dx.doi.org/10.1080/08832320309599713

Pearson, Cathy, and Mary Dellman-Jenkins. 1997. "Parental Influence on a Student's Selection of a College Major." College Student Journal 31:301-13.

Petitpas, Al. 1978. "Identity Foreclosure: a Unique Challenge." Personnel and Guidance Journal 56 (9):558-61. http://dx.doi.org/10.1002/j.2164-4918.1978.tb05310.x

Pritchard, Robert E, Gregory C Potter, and Michael S Saccucci. 2004. "The Selection of a Business Major: Elements
Influencing Student Choice and Implications for Outcomes Assessment." Journal of Education for Business 79 (3):1526. http://dx.doi.org/10.3200/JOEB.79.3.152-156

Sacerdote, Bruce. 2001. "Peer Effects with Random Assignment: Results for Dartmouth Roommates." The Quarterly Journal of Economics 116:681-704. http://dx.doi.org/10.1162/00335530151144131

Salawu, AGA, and AA Bagudo. 2008. "Self-concept as a Correlate of Career Choice of Students in Tertiary Institutions in Sokoto State." Nigerian Journal of Guidance and Counselling 7 (1):111.

http://dx.doi.org/10.4314/njgc.v7i1.37035

Saudi Ministry of Higher Education. 2014. "Saudi Arabia - Kingdom of Humanity." Retrieved August 10, 2015 (http://www.mohe. gov.sa/en/studyinside/aboutKSA/Pages/default.aspx)

Simons, Kathleen A, Dana R Lowe, and David E Stout. 2003. "Comprehensive Literature Review: Factors Influencing Choice of Accounting as a Major." Paper presented at the 2003 Academy of Business Education Conference. Retrieved August 10, 2015 (http://abeweb.org/proceedings/ proceedings03/simons.pdf).

Skillman, Gemma Dolorosa. 1999. "Intergenerational Conflict within the Family Context: a Comparative Analysis of Collectivism and Individualism within Vietnamese, Filipino, and Caucasian Families." PhD dissertation, Department of Psychology, Syracuse University.

Sugahara, Satoshi, Gregory Boland, and Andrea Cilloni. 2008. "Factors Influencing Students' Choice of an Accounting Major in Australia." Accounting Education: an International Journal 17 (S1):S37-S54. http://dx.doi.org/10.1080/09639280802009199

Violette, George R. and Douglas G. Chene. 2012. "Factors Influencing Students' Choice of the Accounting Major." The CPA Journal Sept:14-5.

Vroom, Victor Harold. 1964. Work and Motivation. New York: Wiley.

Walker, Erica N. 2006. "Urban High School Students' Academic Communities and their Effects on Mathematics Success." American Educational Research Journal 43 (1):43-73. http://dx.doi.org/10.3102/00028312043001043

Walstrom, Kent A, Thomas P Schambach, Keith $T$ Jones, and William J Crampton. 2008. "Why are Students not Majoring in Information Systems?" Journal of Information Systems Education 19 (1):43-54.

Zhan, Yi Crystal. 2013. "Essays on Ethnicity and Economic Choices." PhD dissertation, University of California, San Diego.

(C) 2015 Guoping Jiang; Licensee Lifescience Global.

This is an open access article licensed under the terms of the Creative Commons Attribution Non-Commercial License (http://creativecommons.org/licenses/by-nc/3.0/) which permits unrestricted, non-commercial use, distribution and reproduction in any medium, provided the work is properly cited. 